\title{
Research on Tax Burden and Enterprise R\&D Efficiency
}

\author{
Song Wenjuan \\ Wuhan Business University, Wuhan, 430056, China \\ email: 51295355@qq.com
}

Keywords: Tax Burden Level; Enterprise R\&D Efficiency, Structural Supply-side Reform

\begin{abstract}
In order to promote economic development and stabilize economic growth, the central government timely proposes the structural supply-side reform. The core of structural supply-side reform lies in improving the effective supply, promoting the transformation of economic structure by system and mechanism reform, and further releasing the dividend system. Under the background of structural supply-side reform, this paper analyzes the relationship between tax burden level and enterprise R\&D(Research and Development) efficiency by descriptive statistics, correlation analysis and regression analysis based on the observed data of 80 enterprises. The research shows that there is a significant negative correlation between tax burden level and enterprise R\&D efficiency.
\end{abstract}

\section{Introduction}

The government is policy-oriented. It aims to use various means to help enterprises reduce their burden and stimulate the vitality of enterprises as a micro-economy, thus encouraging enterprises to further increase their investment in R\&D.[1] For example, measures like deleveraging and cost reduction can help enterprises strengthen their weakness. [2]In this way, enterprises can smoothly transform from "extensive economy" into "intensive economy", from "high growth brought by high investment" to "high growth brought by high technology", so as to enhance the innovation ability of the whole country. However, there exists relatively less research on the impact of tax burden level on R\&D efficiency of different enterprises. [3]Therefore, this paper combines the above factors and studies the impact of tax burden level on enterprises R\&D efficiency under different property rights and leverage levels.[4] This paper has certain theoretical and practical significance for further improving R\&D efficiency of enterprises.

\section{Tax burden of enterprise}

Tax burden of enterprise refers to the ratio between enterprise tax and enterprise income, which belongs to micro tax burden. Qian and Chang (2018) put forward a new calculation method, and reached the conclusion that the turnover tax accounted for the largest proportion of the enterprise tax burden. Cong and Zhou (2017) believed that the economic growth of China has slowed down significantly; the manufacturing profitability has declined while the enterprise tax burden has been still increasing since 2012. Xie and Li (2016) believed that turnover tax burden of enterprises increased according to the increase of gross profit under the "Business Tax Replaced with Value Added Tax" policy. According to the substitution relationship of turnover tax burden, the enterprise tax burden also increased accordingly. Li(2016) believed that the micro-tax burden of enterprises is higher than the macro-tax burden in China. [5] It is necessary to reduce the burden of enterprises through positive tax clearance, further deepen the tax reform and give play to the regulatory role of tax on economic operation, so as to create a fairer and legal market environment for enterprises. Macro tax burden at the micro level is of great significance to industry development and industry restructuring. It is also the basis of macro tax burden research. Therefore, with the advent of the era of big data, macro tax burden research at the micro level will play an increasingly important role. 


\section{Theoretical analysis and hypothesis testing}

In the fierce market competition, the core competitiveness of enterprises usually comes from their own valuable, scarce, inimitable and irreplaceable heterogeneous resources(Baum and Dobbin, 1991). The intangible assets created by enterprises through R\&D activities, and the experience and capability cultivated in this process just belong to this kind of resources(Grant,1999). For enterprises, $R \& D$ plays an important role in their development process. When new technology is developed, old technology will be eliminated, and $R \& D$ enterprises will replace the original enterprises to become new monopolists. Successful innovation can enable enterprises to obtain short-term excess profits in the temporary monopoly control. Therefore, the government should actively support and encourage innovation activities through policy guidance in the face of the potential risks that $R \& D$ activities may pose to enterprises. Actually, most countries tend to adopt tax incentives to support innovation activities, and tax incentives do improve the efficiency of R\&D. Therefore, based on the above analysis, this paper argues that there is a significant negative correlation between tax burden level and R\&D efficiency.

\section{Empirical research design}

\subsection{Sample selection and data sources}

This paper selects effective sample data from 80 enterprises. By descriptive statistics, correlation analysis and regression analysis, the influence of explanatory variables on the explained variables was studied. In this paper, Excel 2010 is used to preprocess the original data, and Stata 12.0 statistical software is used to analyze the data and get the final results.

\subsection{Definition of variables}

\subsubsection{Explained variables}

R\&D Input Density: Most studies measure the R\&D investment level of enterprises only by considering R\&D investment or R\&D achievements. This paper focuses on the of R\&D investment level of enterprises, and the considered variables include $R \& D$ investment and $R \& D$ human capital investment.

\subsubsection{Explanatory variables}

Tax burden level: using the research results of Wu (2009) as reference, this paper uses the ratio of income tax expenses to pre-tax profit as an index to measure the tax burden level of enterprises.

\subsubsection{Controlled variables}

After literature review, this paper includes controlled variables including company size (Size), whether chairman and general manager are dual (Dual), management ownership (Mhn), shareholding ratio of the largest shareholder (First) and increase rate of business revenue (Growth). In addition, virtual variables include industry and year. In this paper, when dividing the leverage level of enterprises, the median of asset-liability ratio of enterprises in collected samples is treated as the standard. Those above the median are divided into the enterprises with higher leverage level, and those below the median are divided into the enterprises with lower leverage level.

\subsection{Model building}

According to the research idea and hypothesis of this paper, and in order to observe the relationship between enterprise tax burden and enterprise $R \& D$ efficiency, the following regression model is constructed: $\mathrm{R} \& \mathrm{D}=\alpha 0+\alpha 1$ Taxi, $\mathrm{t}+\alpha 2$ Sizei, $\mathrm{t}+\alpha 3$ Duali, $\mathrm{t}+\alpha 4$ Mhni, $\mathrm{t}+\alpha 5$ Firsti, $\mathrm{t}+\mathrm{a} 6$ Growthi, $\mathrm{t}+\sum$ Year $+\sum$ Industry $+\varepsilon_{\mathrm{i}, \mathrm{t}}$

Among them, $\alpha 0$ represents the intercept, $\alpha 1$ to $\alpha 6$ is the regression coefficient of different explanatory variables , $\varepsilon \mathrm{i}$, $\mathrm{t}$ refers to the error term, i refers to the number of sample enterprises, $\mathrm{t}$ refers to the year. 


\subsection{Empirical analysis}

\subsubsection{Descriptive statistics}

Table 1 is a descriptive statistical result of the main variables. From table 2, we can find that the average R\&D efficiency of enterprises is only $4.28 \%$. Generally speaking, the R\&D input of listed companies is not enough, and there is a certain gap between different enterprises in R\&D efficiency. The average actual tax burden of enterprises accounts for $15.31 \%$, while the maximum value accounts for $55.34 \%$, the minimum value accounts for $0.18 \%$. There is a big gap among the actual tax burden of different enterprises.

Table 1 Results of descriptive statistics analysis

\begin{tabular}{|c|c|c|c|c|c|}
\hline Variables & minimum & maximum & average & $\begin{array}{c}\text { standard } \\
\text { deviation }\end{array}$ & Median \\
\hline R\&D & 0.0004 & 0.2414 & 0.0428 & 0.0410 & 0.0343 \\
\hline Tax & 0.0018 & 0.5056 & 0.1531 & 0.0847 & 0.1458 \\
\hline Lev & 0.0080 & 0.9849 & 0.3892 & 0.1978 & 0.3730 \\
\hline Size & 17.8061 & 27.9617 & 22.0348 & 1.2011 & 21.8879 \\
\hline Dual & 0 & 1 & 0.3805 & 0.4856 & 0 \\
\hline Mhn & 0 & 1.6601 & 0.2362 & 0.3335 & 0.0258 \\
\hline First & 0.0362 & 0.8909 & 0.3438 & 0.1443 & 0.3272 \\
\hline Growth & -0.9919 & 174.8993 & 0.3875 & $\mathrm{a} 4.4403$ & 0.0871 \\
\hline
\end{tabular}

The average asset liability ratio is $38.92 \%$. Generally speaking, risk management of enterprise debt is well. In the empirical analysis, this paper divides the enterprise into two groups according to the median (37.30\%) of asset-liability ratio (Lev). Respectively, the enterprise group with higher leverage level and the enterprise group with lower leverage level, and further analyzes the different groups.

\subsubsection{Correlation analysis}

Table 2 is the correlation among different main variables. The results show that there is a significant negative correlation between R\&D efficiency and enterprise tax burden level which proves the hypothesis. At the same time, the correlation coefficients between the explanatory variables and the control variables are not high; the coefficients are less than 0.5. It indicates the weak correlation between the explanatory variables and control variables. In addition, we can preliminarily exclude the effect of multiple co linearity between variables on regression results.

Table 2 correlation coefficient test among different variables

\begin{tabular}{|c|c|c|c|c|c|c|c|}
\hline Variables & R \&D & Tax & Size & Dual & Mhn & First & Growth \\
\hline R\&D & 1 & & & & & & \\
\hline Tax & -0.1315 & 1 & & & & & \\
\hline Size & -0.2831 & -0.0177 & 1 & & & & \\
\hline Dual & 0.0682 & 0.0175 & -0.1382 & 1 & & & \\
\hline Mhn & 0.2314 & -0.0076 & -0.3567 & 0.3105 & 1 & & \\
\hline First & -0.1382 & 0.0076 & 0.1884 & -0.0175 & -0.0650 & 1 & \\
\hline Growth & -0.0111 & -0.0122 & -0.0335 & -0.0151 & -0.02114 & -0.0203 & 1 \\
\hline
\end{tabular}

\subsubsection{Regression analysis}

This part analyzes the effect of leverage ratio on the relationship between tax burden and R\&D efficiency. Taking the median (37.30\%) of asset-liability ratio as the standard, this study divided enterprises into two groups. They are enterprise group with high-leverage and enterprise group with low-leverage. After that, regression analysis was carried out respectively. Table 2 is the result of regression analysis. According to Table 3, there is a significant negative correlation between tax burden and R\&D efficiency for enterprises with lower leverage and enterprises with higher leverage. Therefore, in order to explore whether there is any difference in the effect of tax burden on $R \& D$ efficiency for enterprises with different leverage levels, this paper further analyzes the difference of 
inter group coefficients between two groups of samples. The results show that chi2 $(1)=7.96$, Prob $>$ chi $2=0.0048$. In other words, the difference between groups was significant at level $1 \%$, and hypothesis 3 is verified in this way. The empirical results show that when the enterprise has low leverage, reducing the enterprise tax burden has a more significant effect on improving $R \& D$ efficiency.

Table 3 tax burden and enterprise R\&D Efficiency

\begin{tabular}{|c|c|c|}
\hline Variables & $\begin{array}{c}\text { Enterprises with Low } \\
\text { leverage }\end{array}$ & Enterprises with High leverage \\
\hline Tax & 0.0688 & -0.00234 \\
& -6.01 & -3.52 \\
\hline Size & -0.0070 & -0.0031 \\
& -5.93 & -6.17 \\
\hline Dual & 0.0013 & -0.0018 \\
& 0.61 & -1.51 \\
\hline Mhn & 0.0099 & 0.0104 \\
& 3.43 & 4.83 \\
\hline First & -0.0225 & -0.0043 \\
& -3.29 & -1.11 \\
\hline Growth & -0.0003 & -0.0002 \\
& -1.02 & -1.62 \\
\hline Constant term & 0.1947 & 0.0825 \\
& 7.20 & 7.09 \\
\hline Industry & controlled & controlled \\
\hline Year & controlled & controlled \\
\hline Adj-R2 & 0.2567 & 0.2293 \\
\hline F value & 30.49 & 26.40 \\
\hline Sample size & 2000 & 2000 \\
\hline
\end{tabular}

\section{Conclusion}

The empirical results of this paper draw the following conclusions. Firstly, reducing the enterprise tax burden can motivate enterprises to increase R\&D efficiency. Secondly, for both state-owned enterprises and private enterprises, tax burden has a significant negative correlation with their R\&D efficiency. In conclusion, reducing enterprise tax burden from the macro level is helpful to improve the business environment, stimulate the vitality of micro-economy and improve R\&D enthusiasm and efficiency of enterprises, so as to enhance core competitiveness of enterprises and further improve the innovation ability of the whole society.

\section{Acknowledgement}

In this paper, the research was sponsored by Ph.D. Programs Foundation of Wuhan Business University: Research on Tax Burden and Enterprise R\&D Efficiency (Project No. 2017KB004).

\section{References}

[1] An assessment of proposed energy resource tax reform in Russia: A static general equilibrium analysis[J] . Anton Orlov. Energy Economics. 2015

[2] Do investors care about corporate taxes?[J] . Chris Brooks, Chris Godfrey, Carola Hillenbrand, Kevin Money. Journal of Corporate Finance. 2016

[3] On the influence of oil prices on economic activity and other macroeconomic and financial variables*[J]. OPEC Energy Review. 2009 (4)

[4] Two-sector perspectives on the effects of payroll tax cuts and their financing [J] . Alberto Petrucci, Edmund S. Phelps. Journal of Public Economics. 2008 (1) 
[5] Does recent empirical evidence support the existence of international corporate tax competition?[J]. Richard S. Simmons. Journal of International Accounting, Auditing and Taxation . $2006(1)$ 